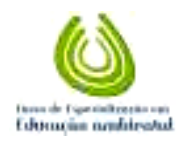

KELLING \& COSTA, vol.(4), n4, p. 638-646, 2011.

Monografias Ambientais (e-ISSN: 2236-1308)

REMOA

\title{
EDUCAÇÃO E GESTÃO AMBIENTAL NA COTRISEL - COOPERATIVA TRITÍCOLA SEPEENSE LTDA
}

\author{
Vera Lúcia Vargas Kelling', Vânia Medianeira Flores da Costa² \\ ${ }^{1}$ Acadêmica da Especialização em Educação Ambiental da UFSM \\ ${ }^{2}$ Professora da UFSM
}

\section{RESUMO}

Este artigo traz considerações sobre a Educação e Gestão Ambiental na COTRISEL - Cooperativa Tritícola Sepeense Ltda. $O$ estudo procura mostrar que as questões que envolvem a degradação do Meio Ambiente por meio dos processos industriais tornam-se uma das principais preocupações das grandes empresas. Chegando a conclusão que a inserção da Educação Ambiental aos recursos humanos da empresa prioriza a política de prevenção, partindo do princípio que a preservação do Meio Ambiente é uma responsabilidade coletiva. Da mesma forma que as ações de Gestão Ambiental desenvolvidas pela Cooperativa visam minimizar os impactos produzidos pelos processos produtivos da empresa e, dessa forma, contribuir para a sustentabilidade do planeta.

PALAVRAS-CHAVE: Educação Ambiental, Desenvolvimento Sustentável, Gestão Ambiental.

\section{EDUCATION AND ENVIRONMENTAL MANAGEMENT IN COTRISEL - COOPERATIVE WHEAT SEPEENSE LTDA}

\begin{abstract}
This article presents considerations on Education and Environmental Management in COTRISEL - Cooperative wheat Sepeense Ltda. The study seeks to show that the issues involve the deterioration of the environment through industrial processes become a major concern of large companies. Reaching the conclusion that the inclusion of environmental education to human resources the company gives priority to prevention policy, assuming that the preservation of the environment is a collective responsibility. Just as the actions undertaken by the Cooperative Environmental Management aim to minimize the impacts produced by processes of the company and thereby contribute to the sustainability the planet.
\end{abstract}

KEY WORDS: Environmental Education, Sustainable Development, Management Environment.

\section{INTRODUÇÃO}

A Revolução Industrial alavancou importantes transformações sociais e econômicas em todo o mundo. Em consequência, o trabalho humano foi sendo substituído pela tecnologia com o 


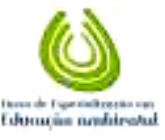

\section{KELLING \& COSTA, vol.(4), nº, p. 638-646, 2011. Monografias Ambientais (e-ISSN: 2236-1308)}

REMOA

objetivo de gerar mais produtividade e maiores lucros, impulsionada pelo sistema capitalista. A aceleração da economia e a decorrente expansão das empresas causaram sucessivas agressões ao Meio Ambiente. Visualizando o problema, houve então, a necessidade de que os gestores dessas empresascriassem estratégias que contemplassem o desenvolvimento de produção integrado a práticas ambientais de proteção aos recursos naturais.

Juntamente com a aquisição de tecnologias modernas que produzissem menor impacto ao Meio ambiente, tornou-se indispensável a criação de políticas específicas de Gestão Ambiental. Da mesma forma, a Educação Ambiental aplicada às empresas objetiva propor atitudes que proporcionem a seu quadro de funcionários a alteração de comportamento, tornando a Empresa ambientalmente sustentável.

Assim, as empresas buscam o aprimoramento de suas práticas para proteger ambientalmente o meio onde estão inseridas, criando um elo de reciprocidade e de convivência saudável com a comunidade, baseados na Educação e na Gestão Ambiental.

\section{EDUCAÇÃO AMBIENTAL}

Nos últimos séculos o homem evoluiu seu conhecimento e, por meio de estudos e de pesquisas, houve um amplo desenvolvimento das ciências e da tecnologia. O conhecimento proporcionou um novo estilo de vida para a sociedade em geral, fazendo com que novos valores fossem agregados ao cotidiano desses indivíduos. Entre esses valores, destaca-se o respeito com o meio onde estão inseridos.

O Meio Ambiente começou a ser visto como parte fundamental para a sobrevivência de todos os seres do planeta. Surge então a Educação Ambiental com o objetivo de integrar o Meio Ambiente e o homem, apostando no entendimento de que ambos necessitam de uma convivência racional e equilibrada.

De acordo com a Secretaria de Educação Continuada, Alfabetização e Diversidade (Secad/MEC), os primeiros registros da utilização do termo "Educação Ambiental" datam de 1948, num encontro da União Internacional para a Conservação da Natureza (UICN) em Paris, porém os rumos da Educação Ambiental são realmente definidos a partir da Conferência de Estocolmo, em 1972, em que se atribui a inserção da temática da Educação Ambiental na agenda internacional. Em 1975 lança-se em Belgrado (na então lugoslávia), o Programa Internacional de Educação Ambiental, no qual são definidos os princípios e orientações para o futuro (Cadernos Secad, 2007).

Em 1977, acontece em Tbilisi, na Georgia (ex-União Soviética), a Conferência Intergovernamental sobre Educação Ambiental, cuja organização ocorreu a partir de uma parceria entre a Unesco e o então recente Programa de Meio Ambiente da ONU (Pnuma). Foi deste encontro - firmado pelo Brasil - que saíram as definições, os objetivos, os princípios e as estratégias para a Educação Ambiental que até hoje são adotados em todo o mundo (Cadernos Secad, 2007).

Outro documento internacional de extrema importância é o Tratado de Educação Ambiental para Sociedades Sustentáveis e Responsabilidade Global elaborado pela sociedade civil planetária em 1992 no Fórum Global, durante a Conferência das Nações Unidas sobre Meio Ambiente e Desenvolvimento (Rio 92). Enfatiza os processos participativos voltados para a recuperação, 


\title{
KELLING \& COSTA, vol.(4), n4, p. 638-646, 2011. Monografias Ambientais ～(e-ISSN:2236-1308)
}

REMOA

conservação e melhoria do meio ambiente e da qualidade de vida. O Tratado tem bastante relevância por ter sido elaborado no âmbito da sociedade civil e por reconhecer a Educação Ambiental como um processo político dinâmico, em permanente construção, orientado por valores baseados na transformação social (Cadernos Secad, 2007).

A Agenda 21, documento também concebido e aprovado pelos governos durante a Rio 92, é um plano de ação para ser adotado global, nacional e localmente, por organizações do sistema das Nações Unidas, governos e pela sociedade civil, em todas as áreas em que a ação humana impacta o meio ambiente. Além do documento em si, a Agenda 21 é um processo de planejamento participativo que resulta na análise da situação atual de um país, estado, município, região, setor e planeja o futuro de forma sócio-ambientalmente sustentável.(Cadernos Secad, 2007).

A Educação Ambiental surge no Brasil muito antes da sua institucionalização no governo federal. Temos a existência de um persistente movimento conservacionista até o início dos anos 70, quando ocorre a emergência de um ambientalismo que se une às lutas pelas liberdades democráticas, manifestadas através da ação isolada de professores, estudantes e escolas, por meio de pequenas ações de organizações da sociedade civil, de prefeituras municipais e governos estaduais, com atividades educacionais voltadas a ações para recuperação, conservação e melhoria do meio ambiente. Nesse período também surgem os primeiros cursos de especialização em Educação Ambiental (Cadernos Secad, 2007).

O processo de institucionalização da Educação Ambiental no governo federal brasileiro teve início em 1973 com a criação da Secretaria Especial do Meio Ambiente (Sema), vinculada à Presidência da República.

A Educação Ambiental insere-se no cotidiano dos indivíduos objetivando a compreensão de todos os elementos que compõem a natureza, no sentido de um uso racional dos recursos naturais, como afirma Dias (1998 p.63): “a Educação Ambiental deve permitir a compreensão da natureza complexa do meio ambiente e interpretar a interdependência entre os diversos elementos que conformam o ambiente, com vistas a utilizar racionalmente os recursos do meio na satisfação material e espiritual da sociedade, no presente e no futuro de cada país, região e comunidade, sob uma perspectiva histórica". Também sobre a Educação Ambiental, Carvalho (2005), assim se refere:

\begin{abstract}
A EA fomenta sensibilidades afetivas e capacidades cognitivas para uma leitura do mundo do ponto de vista ambiental. Dessa forma, estabelece-se como mediação para múltiplas compreensões da experiência do indivíduo e dos coletivos sociais em suas relações com o ambiente. Esse processo de aprendizagem, por via dessa perspectiva de leitura, dá-se particularmente pela ação do educador como intérprete dos nexos entre sociedade e ambiente e da EA como mediadora na construção social de novas sensibilidades e posturas éticas diante do mundo (p. 78).
\end{abstract}

Para a UNESCO (1987) a Educação Ambiental é um processo permanente no qual os indivíduos e a comunidade tomam consciência do seu meio ambiente e adquirem conhecimentos, habilidades, experiências, valores e a determinação que os tornam capazes de agir, individual ou coletivamente, na busca de soluções para os problemas ambientais, presentes e futuros.

Assim, todos os encontros, documentos e opiniões reiteram e relacionam a Educação Ambiental como um importante aspecto à consciência ética em relação Meio Ambiente. Nesse 
contexto evidenciou-se a necessidade de as empresas aprimorarem suas tecnologias e conscientizar seus colaboradores para as questões ambientais, através da Gestão Ambiental.

\section{GESTÃO AMBIENTAL NAS EMPRESAS}

De acordo com Maimon (1996), a Gestão Ambiental é definida como um conjunto de procedimentos para gerir ou administrar uma organização, de forma a obter o melhor relacionamento com o meio ambiente.

Segundo esse mesmo autor, a Gestão Ambiental (GA) é entendida como uma forma de ajustar o desenvolvimento de uma empresa à proteção ambiental, ou seja, deve ser retirado da natureza apenas o que pode ser reposto, ou então, deve ser recuperada a degradação ambiental causada.

Donaire (1999, p.15), afirma que "no principio as organizações precisavam preocupar-se apenas com a eficiência dos sistemas produtivos", gerar um lucro cada vez maior, padronizar cada dia mais o desempenho dos funcionários, essa visão industrial que as organizações idealizavam, foi tornando-se, ao longo dos anos, cada vez mais enfraquecida.

O mesmo autor afirma que:

Os administradores começaram a ver que suas organizações não se baseavam somente nas responsabilidades referentes a resolver problemas econômicos fundamentais (o que produzir, como produzir e para quem produzir) têm presenciado o surgimento de novos papéis que devem ser desempenhados, como resultado das alterações no ambiente em que opera (p.15).

Ainda Donaire (1999), afirma que o retorno do investimento, antes, entendido simplesmente como lucro e enriquecimento de seus acionistas, ora em diante, passa, fundamentalmente, pela contribuição e criação de um mundo sustentável.

Esses processos de produção de conhecimento têm oportunizado o desabrochar de práticas positivas e proativas, que possibilitam de métodos e de experiências que comprovam, mesmo que em um nível ainda pouco disseminado, a possibilidade de fazer acontecer e tornar real o novo, necessário e irreversível, caminho de mudanças.

Segundo Souza (1993), as estratégias de marketing ecológico, adotadas pela maioria das empresas, visam a melhoria de imagem tanto da empresa quanto de seus produtos, através da criação de novos produtos verdes e de ações voltadas pela proteção ambiental.

De acordo com Andrade at al. (2002), no Brasil a partir de 1975, foram sendo criados órgãos ambientais, legislações e controles nos nível federal e estadual. O controle dos municípios surgiu na sequência. As grandes empresas nacionais e multinacionais foram as primeiras a instituir e adotar medidas ambientais, criando departamentos com essa finalidade. As empresas contemporâneas têm a preocupação de implantar auditorias ambientais objetivando identificar problemas ambientais na empresa e a inserindo a empresa nas normas legais exigidas pela legislação ambiental.

A preocupação com as questões ambientais nas empresas se evidenciou nas décadas de 1970 a 1980. Segundo Callenbach et al. (1993), na década de 1980 ampliou-se a conscientização de que os danos ambientais poderiam ser reduzidos através da administração 
ecologicamente correta e que os custos para a reparação desses danos seria mais oneroso que medidas preventivas, o que era estimulada pela sociedade civil e política da época.

De acordo com Rodrigues (2001, p. 5), durante a Conferência da ONU sobre

Desenvolvimento e Meio Ambiente, no Rio de Janeiro, em 1992 (Rio-92) foi definido o seguinte princípio: "A educação ambiental deve integrar conhecimentos, aptidões, valores, atitudes e ações. Deve converter cada oportunidade em experiências educativas de sociedades sustentáveis (Tratado de Educação Ambiental para Sociedades Sustentáveis e Responsabilidade Global)".

Os instrumentos de gestão ambiental objetivam melhorar a qualidade ambiental e o processo decisório. São aplicados a todas as fases dos empreendimentos e poder ser: preventivos, corretivos, de re-mediação e pró-ativos, dependendo da fase em que são implementados. Nessa perspectiva, os empresários começam a entender que o desgaste causado pelas formas de produção à natureza é incompatível com a sua regeneração, sendo fundamental a atuação social e ética das empresas na busca pelo desenvolvimento sustentável.

\title{
DESENVOLVIMENTO SUSTENTÁVEL
}

A partir da segunda metade do século XIX, a percepção que a degradação ambiental estava alcançando rumos incontroláveis, proporcionou que estudos fossem realizados, e assim, surgiram as primeiras reações no sentido de que ações fossem realizadas para diminuição dos danos ao meio ambiente. Batista e Chaves (2007), afirmam que:

\begin{abstract}
A existência de uma sociedade sustentável ocorre quando idéias, saber, tecnologias, equipamentos e o capital natural são combinados para produzirem os bens e serviços que atendam às necessidades e desejos humanos, sem pôr em risco de degradação ou exaustão o sistema global que dá suporte e/ou sustenta todos as formas de capital. Sustentabilidade significa o reconhecimento de limites biofísicos colocados, incontornavelmente pela biosfera, no processo econômico. Existe a necessidade de estratégias em que a natureza seja levada em consideração também como fator restritivo, que deve ser utilizado com máxima produtividade e sem efeitos degradantes, a fim de que, no futuro, a disponibilidade dos recursos naturais esteja preservada. Considerações ambientais devem ser misturadas com propostas de eqüidade social, eficiência econômica e factibilidade política, pois a sustentabilidade pressupõe que os custos ambientais sejam internalizados pelo mercado (p. 32).
\end{abstract}

Segundo Mousinho (2003), em 1948 autoridades reconheceram formalmente os problemas ambientais, na reunião do Clube de Roma, que constatou a falência dos recursos naturais e solicitou o estudo intitulado Limites do Crescimento, liderado por Dennis Meadows. Esse estudo detectou que a degradação ambiental decorre, principalmente, do crescimento populacional e da exploração sem controle dos recursos naturais. O resultado desses estudos propiciou subsídios para a idéia desenvolvimento aliados à preservação.

Ainda Mousinho (2003), afirma que a Organização das Nações Unidas (ONU) promoveu a Conferência de Estocolmo, em 1972, com a finalidade de discutir e encontrar soluções para o problema ambiental do planeta. Como resultado, houve a criação da Declaração sobre o Ambiente Humano, que introduziu na Agenda Política Internacional a dimensão ambiental 


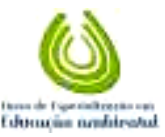

KELLING \& COSTA, vol.(4), n4, p. 638-646, 2011. Monografias Ambientais

(e-ISSN: 2236-1308)

REMOA

como condicionadora e limitadora do modelo tradicional de crescimento econômico e do uso dos recursos naturais. A Declaração determinou ao mundo que "tanto as gerações presentes como as futuras tenham reconhecido como direito fundamental a vida num ambiente sadio e não degradado".

As metas propostas pelo Relatório sugerem que as organizações do desenvolvimento devem adotar a estratégia de desenvolvimento sustentável; a comunidade internacional deve proteger os ecossistemas supranacionais como a Antártica, os oceanos, o espaço; as guerras devem ser banidas e que a ONU deve implantar um programa de desenvolvimento sustentável. Mousinho (2003, p. 26), ao referir-se ao desenvolvimento sustentável, Gro Harlem Brundtland, ex-primeira-ministra da Noruega que presidiu a Comissão Mundial de Meio Ambiente e Desenvolvimento em 1987, declara que: "satisfaz as necessidades presentes, sem comprometer a capacidade das gerações futuras de suprir suas próprias necessidades". Isto é, todo o desenvolvimento das sociedades deve ser realizado, sem que para isso, os recursos naturais do planeta sejam degradados.

Nesse sentido, os sistemas de produção, as políticas, a transformação, o comércio, os serviços - agricultura, indústria, turismo, mineração - e o consumo têm de existir preservando a biodiversidade do planeta.

De acordo com Donaire (1999), o desenvolvimento sustentável, além de equidade social e equilíbrio ecológico, apresentam como terceira vertente principal, a questão do

desenvolvimento econômico. Induz um espírito de responsabilidade comum como processo de mudança, no qual a exploração de recursos materiais, os investimentos financeiros e as rotas do desenvolvimento tecnológico deverão adquirir sentidos harmoniosos.

Nesse sentido, o desenvolvimento da tecnologia deverá ser orientado para metas de equilíbrio com a natureza e de incremento da capacidade de inovação dos países em desenvolvimento, e o progresso será entendido como fruto de maior riqueza, maior benefício social equitativo e equilíbrio ecológico.

Assim, todas as formas de relação do homem com a natureza devem ser realizadas com a preocupação de que os recursos naturais são finitos e necessitam ser utilizados com moderação. O desenvolvimento de uma empresa deve ser efetivado objetivando a geração de riquezas, porém levando em consideração a qualidade ambiental do planeta.

\section{GESTÃO AMBIENTAL NA COOPERATIVA TRITÍCOLA SEPEENSE LTDA - COTRISEL}

A preservação do Meio Ambiente é uma premissa que acompanha as atividades da Cooperativa Tritícola Sepeense Ltda, sendo que a Gestão da qualidade do ar se constitui em uma das principais preocupações dos gestores da empresa.

Assim, há a preocupação de que partículas poluentes originárias da secagem e beneficiamento dos grãos sejam contidas dentro da própria indústria, proporcionando qualidade do ar à comunidade circunvizinha da Cooperativa.

Nesse sentido, a Cooperativa está sempre em busca de novas tecnologias que possam dar maior proteção ao Meio Ambiente. Possui equipamentos de controle de poluição na Matriz em São Sepé e nas Filiais - Unidades de Formigueiro, Restinga Sêca, São Pedro do Sul e Vila Nova do Sul.

A Cooperativa Tritícola Sepeense Ltda, entendendo ser primordial a utilização sustentável da 
água, implantou um moderno sistema de captação de água da chuva nas novas instalações do Mercado Cotrisel, localizado em São Sepé.

O sistema de aproveitamento da água pluvial utilizado no Mercado é composto por subsistemas: captação, condução e armazenamento. A captação é feita por calhas instaladas nos telhados; a condução ou encaminhamento se dá por meio de tubulação hidráulica, que leva a água de chuva por tubos verticais, sendo que os horizontais é que vão conduzir até o reservatório. Essa água é utilizada para atender a necessidade das bacias sanitárias, torneiras e limpeza em geral.

Inserida nesse contexto, preocupada com a conscientização social de uma melhor qualidade ambiental, a Cooperativa Tritícola Sepeense Ltda instalou no Mercado Cotrisel, localizado em São Sepé, equipamentos de tratamento de efluentes, sendo que os poluentes resultantes do processo produtivo são canalizados em galerias, para posterior tratamento, contribuindo para a melhoria da qualidade de vida e preservação do meio ambiente. Assim, esse avançado sistema de tratamento de efluentes devolve à natureza toda a água utilizada nos processos de manutenção do empreendimento, sem comprometer os recursos naturais.

Inserida nesse contexto, preocupada com a conscientização social de uma melhor qualidade ambiental, a Cooperativa Tritícola Sepeense Ltda instalou no Mercado Cotrisel, localizado em São Sepé, equipamentos de tratamento de efluentes, sendo que os poluentes resultantes do processo produtivo são canalizados em galerias, para posterior tratamento, contribuindo para a melhoria da qualidade de vida e preservação do meio ambiente. Assim, esse avançado sistema de tratamento de efluentes devolve à natureza toda a água utilizada nos processos de manutenção do empreendimento, sem comprometer o ecossistema.

Na busca do desenvolvimento econômico de forma sustentável, com qualidade de vida e preservação do meio ambiente, a Cooperativa Tritícola Sepeense Ltda. - COTRISEL - está desenvolvendo o programa "Reciclar e Preservar", que tem por objetivo desenvolver ações, levar esclarecimentos e informações que possam despertar, em cada um de seus funcionários, valores imprescindíveis como a importância do meio ambiente e a sua preservação para a perpetuidade da vida no planeta.

Assim, a Cooperativa Tritícola Sepeense desenvolve ações de Educação e de Gestão Ambiental com a proposta de atingir seus funcionários, associados e colaboradores, através do processo de conscientização sobre a problemática ambiental, alertando para a necessidade de mudança do comportamento do homem em relação à natureza, no sentido de promover um modelo de desenvolvimento sustentável.

\section{CONSIDERAÇÕES FINAIS}

Diante do exposto, pode-se concluir que a busca permanente da qualidade ambiental é um processo constante do sistema de gestão ambiental, de acordo com a política estabelecida pela Cooperativa Tritícola Sepeense Ltda. Constata-se que o objetivo principal da Gestão Ambiental da Cotrisel é a busca de melhoria da qualidade ambiental dos serviços, produtos e do ambiente de trabalho da empresa. Nesse sentido, as ações de Gestão Ambiental desenvolvidas pela Cooperativa visam minimizar os impactos produzidos pelos processos 
produtivos da empresa e, dessa forma, contribuir para a sustentabilidade do planeta. Portanto, adotando tecnologias modernas e eficientes, a empresa reduz os riscos e impactos ambientais associados aos processos de produção, auxiliando na manutenção da qualidade do ar, da água e do solo. Da mesma forma, a inserção da Educação Ambiental aos recursos humanos da empresa prioriza a política de prevenção, partindo do princípio que a preservação do Meio Ambiente é uma responsabilidade coletiva. Conclui-se que, as ações de Gestão Ambiental e a consciência de responsabilidade social da Cotrisel são aspectos que fortalecem a imagem positiva da empresa diante de seus funcionários, colaboradores, concorrentes, fornecedores, associados e comunidade.

\section{REFERÊNCIAS}

ALBERTON, Luiz; CARVALHO Fernando Nitz de; CRISPIM, Graciele Hernandez. Evidenciação da Responsabilidade Sócial / Ambiental na perspectiva de um novo contexto empresarial. Disponível em www.congressoeac.locaweb.com.br/. Acesso em 10 de maio de 2009.

ANDRADE, R. O. B; TACHIZAWA, T; CARVALHO, A. B. Gestão ambiental: enfoque estratégico aplicado ao desenvolvimento sustentável. São Paulo: Pearson Education do Brasil Ltda., 2002.

BATISTA, Francisca lone. Gestão Ambiental: Concepção, Consciência Ecológica e Práticas nas Pequenas e Médias Empresas de Transporte Coletivo Urbano da Cidade de Fortaleza. São Paulo: Ática, 2007.

BRASIL. Lei no 9.795 de 27 de abril de 1999. Política Nacional de Educação Ambiental, Presidência da República Federativa do Brasil.

CADERNOS SECAD, Ministério da Educação. Educação Ambiental: aprendizes de sustentabilidade. Brasília: Secad/MEC, 2007.

CALLENBACH, Ernest. Gerenciamento Ecológico - Eco-Manangement - Guia do Instituto Elmwood de Auditoria Ecológica e Negócios Sustentáveis. São Paulo: Ed. Cultrix, 1993.

CAMPOS, L. M. S. SGADA - Sistema de gestão e avaliação de desempenho ambiental: uma proposta de implementação. Tese (Doutorado em Engenharia da Produção) - Universidade Federal de Santa Catarina. Florianópolis, 2001.

CARVALHO, Isabel C. M. Educação Ambiental: A Formação do Sujeito Ecológico. São Paulo: Vozes.

DIAS, G. F. Educação ambiental: princípios e práticas. São Paulo: Gaia, 1998. DONAIRE, Denis. Gestão ambiental na empresa. São Paulo: Atlas, 1999.

FRÓES, César; NETO, Francisco Paulo de Melo. Gestão da responsabilidade social corporativa: o caso brasileiro. Rio de Janeiro: Qualitymark, 2001.

GIL, Antonio Carlos. Gestão de pessoas: enfoque nos papéis profissionais. São Paulo: Atlas, 2001.

LUCHESI, Rubem Bresaola, CANTELLI, Dirceu Junior. Tratamento de Efluentes Líquidos de uma Indústria têxtil e seu reuso. XXVII Congresso Interamericano de Engenharia Sanitária e Ambiental. Campinas, São Paulo, 2007.

MACEDO, R. K. de, Gestão Ambiental - Os Instrumentos Básicos para a Gestão Ambiental de Territórios e de Unidades Produtivas. Rio de Janeiro: ABS, 1994. 


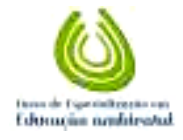

\section{KELLING \& COSTA, vol.(4), n4, p. 638-646, 2011. Monografias Ambientais (e-ISSN: 2236-1308)}

REMOA

MEYER, M. M. Gestão ambiental no setor mineral: um estudo de caso. Dissertação (Mestrado em Engenharia da Produção) - Universidade Federal de Santa Catarina, Florianópolis, 2000.

MAIMON, Dália. Passaporte verde: Gerência ambiental e competitividade. Rio de Janeiro: Qualitymark, 1996.

MOTA, S. Preservação e conservação de recursos hídricos. Rio de Janeiro: ABES,1995.

MOUSINHO, Patrícia. Glossário. In: Trigueiro, A. (Coord.) Meio ambiente no século 21. Rio de Janeiro: Sextante, 2003.

RODRIGUES, Ana Paula da Mota. Rodrigues, Milena Goulart Souza. A Educação Ambiental e os

Parâmetros Curriculares Nacionais: um olhar sobre a transversalidade da questão. Rio de Janeiro, UFRJ, 2001.

SILVA, Gilmar da. Jornal da Unicamp / Assessoria de Imprensa. Cidade Universitária "Zeferino Vaz" Barão Geraldo, Campinas - SP, 2009.

SILVEIRA, Djalma da. ABORDAGEM DAS QUESTÕES AMBIENTAIS: Poluição Industrial-Resíduos Líquidos e Poluição Sonora. Santa Maria, 2009.

SOUZA, M. T. S. Rumo à prática empresarial sustentável. Revista de Administração de Empresas. São Paulo, SP: v.4, n.33, p. 40-52, jul/ago/1993.

UNESCO, Revista O Correio da UNESCO. Rio de janeiro, Ano 15, № 10, Outubro de 1987. 